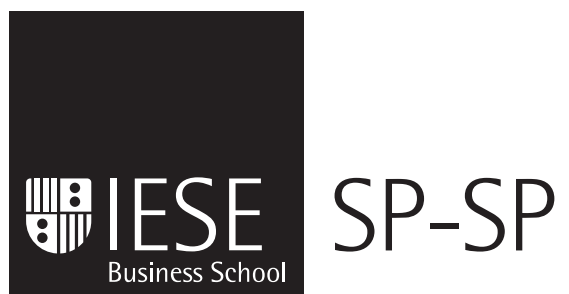

Working Paper

WP no 630

May, 2006

University of Navarra

\title{
TELECOMMUNICATIONS POLICIES: MEASUREMENT AND DETERMINANTS
}

\author{
Jordi Gual
}

Francesc Trillas 
The Public-Private Center is a Research Center based at IESE Business School. Its mission is to develop research that analyses the relationships between the private and public sectors primarily the following areas: regulation and competition, innovation, regional economy and industrial politics and health economics.

Research results are disseminated through publications, conferences and colloquia. These activities are aimed to foster cooperation between the private sector and public administrations, as well as the exchange of ideas and initiatives.

The sponsors of the SP-SP Center are the following:

- Accenture

- Ajuntament de Barcelona

- Official Chamber of Commerce, Industry and Navigation of Barcelona

- BBVA

- Diputació de Barcelona

- Garrigues, Abogados y Asesores Tributarios

- Catalan Government (Generalitat de Catalunya)

- Sanofi-Aventis

- Telefonica

- T-Systems

- VidaCaixa

The content of this publication reflects the conclusions and findings of the individual authors, and not the opinions of the Center's sponsors. 


\title{
TELECOMMUNICATIONS POLICIES: MEASUREMENT AND DETERMINANTS
}

\author{
Jordi Gual* \\ Francesc Trillas**
}

\begin{abstract}
This paper presents new data on telecommunications reform for a cross section of countries. We measure telecommunications reform along two dimensions: entry barriers and regulatory independence. This data set is combined with a comprehensive set of performance, institutional and political data to analyze the determinants of telecommunications policies. We find that entry barriers are positively associated with the degree to which countries have an interventionist legal tradition, but they are unrelated to the partisan ideology of reforming governments. We also find that countries with weak protection of investors' quasi-rents by other means, and countries with a larger incumbent are more prone to create independent regulatory agencies, although this last result is statistically weaker.
\end{abstract}

* Professor of Economics, IESE and "la Caixa"

** Professor, Universitat Autònoma de Barcelona

Classification JEL: L96, L32, F21

Keywords: Telecommunications Policies, Liberalization, Regulation, Entry. 


\section{TELECOMMUNICATIONS POLICIES: MEASUREMENT AND DETERMINANTS*}

\section{Introduction}

The last years of the 20th century were very rich in reform initiatives in the telecommunications sector. Many countries introduced private ownership of the dominant operators, liberalized at least some segments of the industry and introduced new regulatory authorities. Regulatory reform has many dimensions and takes different forms across countries.

The objectives of this study are to measure the reform processes, taking into account such multi-dimensionality, and to analyze the determinants of reform initiatives. We focus on entry barriers (including the degree to which market opening or deregulation policies are asymmetric, or biased in favor or against entrants) and the degree of independence (vis-à-vis their governments) of regulatory authorities. We present new indices, both for entry barriers and for independence, which summarize information on a large number of original variables relevant to these policy areas. We recognize that policies are endogenous, and test hypotheses about their likely determinants.

Although there is a broad consensus among scholars and international institutions (such as the World Bank, the OECD, the International Telecommunications Union, and the European Commission) that opening up the telecommunications sector to competition is both possible and beneficial for social welfare, the precise nature of this liberalization process is still open to debate. Among the unresolved controversial issues surrounding telecommunications reform, there is one that stands out: to what extent should the reform policy favor entrants relative to incumbents? In other words, how biased or asymmetric should regulation be in the marketopening phase? Incumbent operators have huge incumbency advantages in most countries and enjoy significant scope economies, since they operate in several segments of the industry.

\footnotetext{
* Project co-funded by the European Commission within the Sixth Framework Programme. We thank Sandra Jódar and Cristina Blanco for excellent research assistance. Support from the "Public Sector Private Sector" research centre at IESE Business School is gratefully acknowledged. We appreciate the detailed comments made by Lars-Hendrik Röller, Jordi Jaumandreu, Joan Ramon Borrell, Daniel Montolio and Astrid Jung. The paper also benefited from discussions at a CEPR Workshop in Madrid, at the International Industrial Organization Conference in Boston, at the Helsinki meeting of the International Telecommunications Society, at the EARIE Conference in Porto, at the ISNIE Conference in Barcelona, at the Universitat Autonoma de Barcelona, and at the Barcelona Workshop on Industrial and Public Economics (Institut d'Economia de Barcelona-Universitat de Barcelona). We also appreciate the editor's suggestions and the valuable comments of a referee. The authors are responsible for any remaining errors.
} 
However, in most cases they also carry the burden of funding a universal service, and are the main providers of infrastructure. Moreover, asymmetric regulation may lead to regulators favoring particular competitors rather than more competition, allowing the entry of inefficient firms and imposing unnecessary constraints on incumbents. We do not attempt to resolve all these issues in this paper. Rather, we provide measurement tools to address them and we also provide some initial results on the determinants of policy choice, leaving the impact of those policies on performance for further research. ${ }^{1}$ Recent reviews of the interaction between competition and regulation emphasize the need to study these issues in specific contexts. ${ }^{2}$

As far as independence is concerned, some scholars and international institutions advocate the establishment of independent regulators. Indeed, some countries devote a large quantity of resources to try to create at least formally independent regulatory agencies, following the advice if not the rules of the World Bank, the OECD and the European Union. However, there is less discussion of the particular attributes of independent regulators and how to make independence sustainable. Moreover, the measurement of the exact degree of independence, in practice, of specific regulators is a matter of controversy in many countries, such as those of the European Union. On the issue of measurement, we can draw on the academic literature on central bank independence, which analyzes the problem using aggregate indices that take into account several dimensions of independence. ${ }^{3}$ We take a first step in this direction for telecom regulators. It is an important step in our view, insofar as most of the previous empirical literature (see for example Wallsten, 2002, and Fink at al., 2002) has only measured regulatory independence as a binary dummy variable.

We provide a methodology to measure entry barriers and regulatory independence. This methodology can be used (and extended) in later work by the research community, and it provides a ranking of how far countries have gone in lowering entry barriers and separating regulation from governments. It provides a map of telecommunications reform. Comparative assessment of telecommunications reform is an active area of research. ${ }^{4}$ We contribute to this growing literature in three ways:

First, we construct our original indices. Although we analyze telecom reform over two broad dimensions, the policy variables and the parameter estimates incorporate the fact that both entry barriers and regulatory independence are multi-dimensional phenomena. Second, we test hypotheses concerning the determinants of these two dimensions of reform, namely entry

\footnotetext{
${ }^{1}$ In Gual and Trillas (2004) we present an earlier version of this paper where we also analyze the impact of policies taking into account their endogeneity, without clear cut results. See also Besley and Case (2000), Duso and Roller (2003), Beck et al. (2001).
${ }^{2}$ See Armstrong and Sappington (2003 and 2005). These authors claim that even in those cases where competition is superior to regulation, we should expect the transition towards competition to be a "long and winding road." In cases where competition is better than regulation it is not at all clear which policies deliver welfare enhancing competition in the long run. These authors claim that policies that lower consumer switching costs and entry barriers should be preferred over those that favor specific entrants or limit the market share of the incumbents.
${ }^{3}$ For a summary of the literature on central bank independence, see for example Persson and Tabellini (2000, ch. 15). For a comparison of central bank independence and regulator independence, including a discussion of the empirical literature in both fields, see Levine et al. (2005).

${ }^{4}$ See Ros (2003), Wallsten (2001), Fink et al. (2002), Boylaud and Nicoletti (2000), Li et al. (2002), Gutiérrez (2003).
} 
barriers and regulator independence. ${ }^{5}$ Third, we use a battery of institutional indices ${ }^{6}$ to assess how the institutional endowment of countries is related to telecommunications reform.

Our indices give us a ranking of 37 countries in terms of regulatory independence and entry barriers $^{7}$ in telecommunications. Among our preliminary results, we find that entry barriers are positively associated with the degree to which countries have an interventionist tradition, but are unrelated to the partisan ideology of reforming governments. We also find that countries with weak protection of investors' quasi-rents by other means, and countries with a larger incumbent are more prone to create independent regulatory agencies, although this last result is statistically weaker. The ability to commit and the institutional endowment turn out to be key determinants of reform policies. Interest groups are likely to be an important determinant as well, although this result is less robust with our data set.

A contribution to the literature related to ours is Li et al. (2002), which analyzes privatization and liberalization policies separately. ${ }^{8}$ The main differences between our paper and theirs are as follows: First, we measure and analyze the determinants of regulator independence, while they do not. Second, we include privatization as one of the components of the independence package (and alternatively, of the entry barriers package) whereas they analyze it separately. Third, among the determinants of entry barriers, we examine (and find significant) the impact of the judicial tradition of countries and other aspects of the institutional endowment, whereas they do not. They have a larger (cross country and over time) sample, but most of their robust results are consistent with one of ours: the role of interest groups is a key determinant of reforms, although this is not for us one of the most robust results in statistical terms.

The remainder of the paper is organized as follows: Section 2 presents the specification strategy, the hypotheses and the relationship with the existing literature; Section 3 describes the data; Section 4 shows and discusses the results obtained with this data set; and we end up with some concluding remarks in Section 5.

\section{Set Up and Hypotheses}

The objective of our exercise is twofold. First, we want to measure entry barriers and regulator independence. Second, we want to perform an analysis of the determinants of both reform dimensions. Other studies (such as Wallsten, 2001, Ros, 2003, and Gutiérrez, 2003) also provide

\footnotetext{
${ }^{5}$ See LaPorta et al. (1999 and 2002), Kaufmann and Kraay (2002), Henisz and Zelner (2000a and b).

${ }^{6}$ Levine et al. (2005), Stern and Cubbin (2003) and Edwards and Waverman (2006) also stress the importance of developing indices to measure reform, and especially to measure regulatory independence. These papers provide a first assessment of our indices.

${ }^{7}$ Note that our entry indices are an inverse measure of entry barriers. According to our measure, low entry barriers can reflect both the elimination of regulatory barriers to entry and cases where regulation actually favors entry.

8 They claim that interest groups are more successful in more democratic societies, but we do not find their arguments and evidence totally convincing. Beyond possible quibbles on measurement issues, they do not discuss the possibility that more democratic societies are correlated with those with stronger financial sectors and with the development, not the efficacy, of pro-reform interest groups. Indeed, the modern theory of interest groups, as in Grossman and Helpman (2001), argues that interest groups have more clout in less transparent societies. We leave the study of the determinants of the efficacy, instead of the existence, of interest groups, for future research.
} 
a map of both liberalization and regulatory institutions for some countries. We aim at giving more precise and granular measures of both entry barriers and regulator independence. With these more descriptive measures, we then perform an analysis of the likely characteristics of a country that wants to promote lower entry barriers or more regulatory independence. This exercise may be relevant for investors who want to assess the regulatory climate in different countries or to policy analysts who want to predict the likely difficulties that reforms may face in some jurisdictions. The analysis of the likely determinants of policies has been performed before in related areas, for example to study the choice of incentive regulation across U.S. states. $^{9}$

The analysis starts by defining the variables that capture telecommunications reform. We focus on two policy dimensions: entry barriers and regulatory independence. Both variables are themselves multi-dimensional, so the first thing we do is to measure a set of original indicators and aggregate them through indices to obtain one variable for entry barriers and one for regulatory independence.

To analyze the determinants of these specific telecommunication policies, we use a simple reduced-form model that relates policies to interest groups, economic, institutional and sector variables. This specification takes into account the special features of the telecommunications sector. When confronted with the decision to open the industry to competition, the entry barriers faced by new operators are a decisive factor. Policy makers may use a number of tools to favor the entrants. Hence the policy variable, measured with an entry barriers index, will describe both the elimination of regulatory barriers to entry, and cases where regulation actually favors entry ${ }^{10}$ (a higher value in the index will indicate lower entry barriers). A second policy variable will capture how independent regulators are from governments (a higher value in the index will indicate more independence vis-à-vis the government). In this paper, we make no claims about the benefits or otherwise of lower entry barriers or regulator independence in terms of any of the variables used. We constrain ourselves at this stage to measuring these phenomena and quantifying their likely determinants.

The specification we use is the following:

$$
\left.\mathrm{s}=\mathrm{h} \text { (Political Institutions, Interest groups, } q_{-1} \ldots\right)+\mathrm{u}
$$

where $q$ represents the industry outcomes and s represents the policy variables to be explained. $\mathrm{h}$ is a function and $\mathrm{u}$ is an error term. The set of variables $\mathrm{s}$ includes both entry barriers and the independence of regulatory institutions. In equation (1) we include lagged industry outcomes to take into account the potential causal link between past performance variables and current policies.

With this specification strategy in mind, we test two hypotheses derived from the literature on political economy and regulation:

\footnotetext{
${ }^{9}$ See Donald and Sappington (1995).

${ }^{10}$ Elimination of regulatory barriers is usually associated with the term "deregulation," whereas favoring entrants through regulation could be called "asymmetric regulation." Needless to say, liberalization (i.e., allowing competition) can be accompanied both by more regulation (rules of access pricing and quality, for example) or by deregulation (elimination of previous rules). In this sense, our "entry barriers" index captures both deregulation and asymmetric regulation issues.
} 
Hypothesis 1) Entry barriers are negatively associated with more interventionist traditions, and significantly related to the weight of interest groups and the partisan ideology of the reforming government.

First, policies are typically associated with institutional traditions. Policies that lower entry barriers will be more ambitious in countries with a less interventionist tradition (LaPorta et al., 1999 and 2002), since in these countries laws and institutions are there to enlarge the scope of markets and constrain the executive's powers relative to business. Second, many policies have been observed to be partisan, i.e. different political parties, since they represent different constituencies, will implement different policies (Alesina and Rosenthal, 1995). This is opposed to median voter settings, which yield policy platform convergence. Right wing governments, according to this "partisan" view, emphasizing free markets more than redistributive policies, will be more prone to deregulate and create an environment that is favorable to private investment in telecommunications. And third, policies will be influenced by interest groups, which compete in the political arena to obtain favorable policies (see Peltzman, 1976, and Grossman and Helpman, 2001).

Hypothesis 2) Setting up independent regulatory agencies is a policy decision itself, which depends on the institutional endowment of each country and the interest of dominant interest groups in the outcomes of this institutional setting relative to the alternatives.

The explanatory variables for equation (i) will include a number of institutional indices. These political variables influence the choice of policies (market-opening policies as well as regulatory institutions). Using this specification, one can test, for example, whether regulatory independence is necessary or redundant (and hence socially too expensive) once the country has other ways to enforce contracts and credibly commit to stable policies. Levy and Spiller (1996) and Henisz and Zelner (2000b) argue that the creation of independent agencies is one among several options available to countries that want to commit credibly to not expropriating the sunk investments that characterize network industries. Whether this option will be exercised or not depends on the institutional endowment and the structure of interest groups.

\section{Data}

\section{Telecommunications Policy Variables}

We collected data on a number of original variables reflecting telecommunications policies and institutions in 1998 for 37 countries. The description and measurement technique of these original variables can be found in Appendix 1. We initially aggregated the original variables in four indices, two for entry barriers and two for regulatory independence. For the sake of completeness, we also computed one more index in each case (used in Tables 4 and 6). These aggregation techniques are summarized below and more detail is provided in Appendix 2. The values that the indices take for each country and the rankings for each index can be found in Appendix 3. The construction of the indices can be easily replicated. Alternatively, the original variables can be combined in different ways according to the requirements of other researchers. ${ }^{11}$

\footnotetext{
${ }^{11}$ The data on the observations for the original variables are available upon request.
} 
Data have been collected from web pages, legislative texts published by the different regulatory authorities, documents and working papers of the OECD and the International Telecommunications Union (ITU), studies carried out on behalf of the European Commission and articles from specialized journals.

The two indices on entry barriers (entry and entry $(p c)$ ) aggregate information on the following 12 measures or indicators:

- The degree to which entry in the industry is subject to investment conditions of any kind. The more demanding the investment conditions, the more costly it will be for new operators to enter the market, and hence the higher the entry barriers in the industry.

- The average of the number of mobile providers in 1996 and 1997. The number of actual entrants in the mobile industry gives a (certainly imperfect) measure of how easy it has been to enter the industry in the immediate past. Since mobile telephony has been opened to competition prior to (at least local) fixed telephony in many countries, it can give information about actual features of the industry not captured by formal rules that can influence entry barriers in 1998 for the overall industry. In this sense, we treat mobile telephony as part of the telecommunications industry. Entry barriers in the mobile sector can give an idea of entry barriers in fixed telephony and other areas of the telecommunications industry, because investors and regulators are in many cases the same.

- The method of spectrum allocation. Market methods of spectrum allocation (e.g. auctions) make it easier for new operators to enter the industry and hence are associated with lower entry barriers.

- The existence of number portability in fixed and mobile telephony (two variables). Number portability reduces switching costs and consumer inertia and hence involves lower entry barriers for new operators.

- The existence of carrier selection and carrier pre-selection in local, long distance and international telephony (six variables). Carrier selection or pre-selection also reduces switching costs and consumer inertia and hence involves lower entry barriers for new operators.

- The availability of local loop unbundling. This provision, which has been quite controversial in many countries, facilitates the sharing of the incumbents' infrastructure by entrants, thus lowering entry barriers.

Although more variables could no doubt be added, it is clear that the ones included reflect, in practice, the key characteristics of any policy designed to lower entry barriers in telecommunications.

We have associated a metric to each of these variables, with the lowest value for policies that are less favorable to ease of entry and a higher value to policies that are more favorable. These values have been used to compute two indices, namely entry and entry( $p c)$. The difference between entry and entry $(p c)$ is that whereas the former is an ad hoc index that just adds up the values of all the "entry barrier" indicators that have been considered, the latter is a weighted average of three new intermediate variables that summarize all the information in the original indicators using principal components analysis. To compute a unique principal components 
index of entry barriers (entry(pc), each of the three new variables is weighted ${ }^{12}$ by the proportion of the variance of the original variables that each of them explains. The correlation coefficient between entry and entry $(p c)$ is 0.91 .

In the rankings we provide in the appendix, it can be seen that the indices behave according to conventional wisdom, with countries like the U.S., Canada, the U.K., Germany, New Zealand and Chile among the countries with lower entry barriers, and countries like India, Ireland and Ethiopia among the laggards.

Of the 37 countries for which we collected information, 33 had a separate regulatory agency in operation in 1998 (all except Chile, Japan, New Zealand and Israel). Of these, 18 had set up the regulatory agency prior to 1997. In this year, as many as 11 agencies started operating, and four of them started in 1998. The oldest agency is the FCC of the U.S., which started operating in 1934, and the next one at the national level was not created until 1976 in Canada. All the others were created in the 1990s. Therefore, the establishment of separate regulatory agencies is a very recent phenomenon.

The two indices on regulatory independence (indep and indep $(p c)$ ) are based on information which covers the following 11 indicators:

- The degree to which the regulatory agency, as opposed to a ministerial department, is competent in the following policies: licensing, interconnection, tariffs, scarce resources allocation (such as spectrum frequencies and numeration plans), and universal service (five variables). Making final decisions on these policy issues means that these issues are more detached from the short term concerns of politicians, and hence it means that the regulatory agency is more independent from government.

- The degree to which its funding sources are independent of the government's discretion. If its funding does not depend on government decisions, at least in the short run, the agency will feel less constrained in its decisions, and hence it will have more independence from government.

- The rules of appointment of the head of the agency or its board. If the appointment can be made by a minister or cabinet member without any constraints on qualifications or procedures, we associate it with less independence. If the appointment is made by a legislative or other body and/or has to follow specific procedures in terms of publicity and qualifications, the regulator will be more independent from government.

- The length of the term in office for the head of the office or the members of the board. If there is some overlap between the period in office of old appointments and new governments, the agency will not necessarily share the government's preferences, or the agency head will be less worried about re-appointment for a longer period of time.

- The rules about obligations to report to the government, parliament or another official body. The less the regulator has to report to the government, the more independent it is.

\footnotetext{
${ }^{12}$ A similar technique is used for example in Bandiera et al. (2000).
} 
- The number of years since the establishment of the agency's effective operation. Agencies which that have been in operation for longer periods of time will have a reputation of their own and their independence will be more difficult to undermine.

- The incumbent's percentage of private ownership (we also compute two alternative indices with principal components, one for entry and one for independence, where the privatization indicator is part of the entry index instead of the independence index). Arguably, privatization could affect entry policies more than the degree of independence of the regulator. However, if the incumbent is not privatized, any regulator that is separated from the government will face double pressure, both from cabinet ministers and from government officials in the incumbent, and hence he or she will find it more difficult to keep his or her independence.

These original variables reflect mainly legal independence. It is desirable that independence indices also reflect independence in practice. This is difficult at this stage given the limited experience available with independent or at least separate agencies. However, inclusion of the funding variable, the experience of the agency or the privatization variable, move the index as close as possible to a practical one at this stage.

This is a shortcoming of independence measures that has been recognized by other researchers who have analyzed regulatory independence, ${ }^{13}$ and which the availability of more data based on the experience of agencies in their first years of life will correct. Finally, the inclusion in the regression analysis of variables capturing overall regulatory quality could make up, at least partially, for this shortcoming.

Edwards and Waverman (2006) provide the only attempt to build a similar index of regulatory independence. As compared to their measurement exercise, our index uses more variables and has data for more countries (they only analyze EU countries). However, the indices are similar in spirit and in our view both show the way forward in terms of moving the literature on regulation closer to the degree of detail of the literature on central bank independence.

We have assigned a metric to each of the indicators of independence, with the lowest value for policies that give less independence to the regulatory institution and a higher value to policies that give more independence. These values have been aggregated into two indices; indep and indep (pc). The difference between indep and $\operatorname{indep}(p c)$ is that whereas the former is an ad hoc index that just adds up the values in all the "independence" indicators that have been considered, the latter is the result of weighting (by the percentage of variance explained) the four new intermediate variables that summarize all the observations in these indicators using principal components analysis. The correlation coefficient between these two indices is 0.93.

Principal components analysis is a plausible way to aggregate indicators since it removes the effects of variable correlation. That is to say, it aggregates indicators that behave similarly across countries and so provides an aggregate index which focuses on those indicators that provide more information about the variability in the policy choices of the countries in the sample.

\footnotetext{
${ }^{13}$ See Stern and Cubbin (2003), and Edwards and Waverman (2006).
} 


\section{Telecommunications Performance Variables}

Data on the performance of the telecommunications industry is obtained from the International Telecommunications Union (ITU) database. We focus on performance as measured by network penetration and productivity data.

Network penetration is described as main lines per 100 inhabitants (lines100). We focus on the level of this variable in 1998 (lines 10098). Productivity is measured as subscribers per employee in 1994 (e.g. subsworker94). We keep these two variables in the regressions (we also introduced lines 10094 and subsworker98 in some specifications that we do not report, with no significant results).

\section{Political and Institutional Variables}

We have collected a number of political variables on the general quality of government, interest groups, ideology, institutions and the tradition of each country with regard to the state's involvement in the economy.

Our ideological variable ideology has a value of one if the largest party in the government was a right wing party as of January 1st, 1997, and a value of zero if the largest party had any other orientation. We elaborated this variable from Beck et al.'s (2001) original data set. ${ }^{14}$

We have two variables reflecting the interventionist tradition of each country, i.e., the degree to which the state has an inclination to intervene in economic matters. Both of them are collected from LaPorta's web page at the Economics Department of Harvard University. One of them, legal, reports on whether the country's legal system is in the English Civil Law tradition, or in another more interventionist tradition, such as Socialist, French Common Law, German Common Law or Scandinavian Common Law. LaPorta et al. (1999) argue that this variable proxies for the degree of interventionism of the state in economic matters, since English Civil Law was set up to protect owners from the sovereign, whereas traditions such as French Common Law were designed to reinforce the role of the state. The Socialist tradition would be an extreme case of interventionism and the other two would be intermediate cases between English and French. We give a value of 0 to 4 in the order of most interventionist to less (so the order is Socialist, French, German, Scandinavian, English). Moreover, this variable is interesting as a potential instrument because it is exogenous and uncorrelated with performance in telecommunications, since the legal tradition is usually associated with colonization or conquest. The other measure of interventionism, procedures, is the number of steps that a new business has to take in order to start operating, and it is obtained from LaPorta et al. (2002).

We have some variables reflecting the weight of some interest groups in policies of interest, although this is clearly an area that can be expanded in future research. We have the number of telecommunications workers divided by the overall population (staff) as a measure of the size of the

\footnotetext{
14 The original data set on ideologies by Beck et al. labels the largest party in each country's government as left, center, right or non-applicable. However, the way they allocate the left or center label to different largest parties seemed to us a bit inaccurate. For example, they attach the label left both to the Cuban government and to the Clinton administration in the US, whereas the Prodi administration in Italy and the center-left ruling coalition in Chile are allocated the Center label. The way they allocate the right label seemed to us more clear cut.
} 
incumbent, and the percentage of urban population (urbanpop) as a measure of the size of a social group demanding new services and hence a priori in favor of telecom liberalization. Both measures take the observations for 1994 (staff94 and urbanpop94). As far as the staff variable is concerned, our purpose is not to capture the influence of the current workforce on the policies, but instead to give a proxy of the clout of the firm as an interest group. In this sense, the size of the company a few years before the study may describe the historical and inherited power of the company as a lobby. If the incumbent company was very large four years before the year in which it is studied, that year it will continue to be a powerful lobby, even if there have been layoffs and changes in the workforce, especially as long as the company is still the dominant operator.

We have three variables reflecting the general quality of government, obtained from Kaufmann and Kraay (2002). These are regqual, goveff and rulelaw, and they are composite indices measuring, respectively, the general quality of government, government effectiveness and the rule of law.

And we initially explored one additional variable, instconst, which is an index of institutional constraints on executive bodies, first used in Henisz and Zelner (2000). We used the average for this index between 1945 and 1975. This index gives a measure of the ability of governments to commit themselves or their successors to policies that prevent the expropriation of investments.

Table 1 reports on the correlation matrix of these institutional and political variables for our observations, plus our indep( $p c)$ index. The table clearly shows that these variables measure different phenomena, and that not taking some of them into account may lead us to omit some important influences in the analysis. The rule of law index, the government effectiveness index and the regulatory quality index are highly positively correlated. The legal origin and the number of procedures to set up a new business are highly negatively correlated. Surprisingly, our index of regulatory independence is not highly correlated with any of the other institutional indices. We tackle this issue more in depth below, when we discuss our preliminary results.

\section{Table 1}

Correlation Between Sector-Specific and General Regulation Variables

\begin{tabular}{|l|l|l|l|l|l|l|l|}
\hline & regqual & indep(pc) & goveff & rulelaw & legal & instconst & procedures \\
\hline regqual & 1 & & & & & & \\
\hline indep(pc) & 0.0493 & 1 & & & & & \\
\hline goveff & 0.9221 & 0.0093 & 1 & & & & \\
\hline rulelaw & 0.8743 & -0.087 & 0.9285 & 1 & & & \\
\hline legal & 0.4439 & -0.275 & 0.4823 & 0.4963 & 1 & & \\
\hline instconst & 0.3558 & -0.161 & 0.4971 & 0.5447 & 0.6194 & 1 & \\
\hline procedures & -0.639 & 0.0845 & -0.648 & -0.664 & -0.775 & -0.6393 & 1 \\
\hline
\end{tabular}

We also have data on the GDP per capita in 1998 in dollar terms (Gdpcap98) to control for the level of development in each country, which may also influence telecom performance. There is a high correlation between regulatory quality (and also government effectiveness and rule of law) and GDP per capita. Figure 1 points to a non-linear positive association between these variables. 


\section{Figure 1}

Regulatory Quality and GDP per Capita

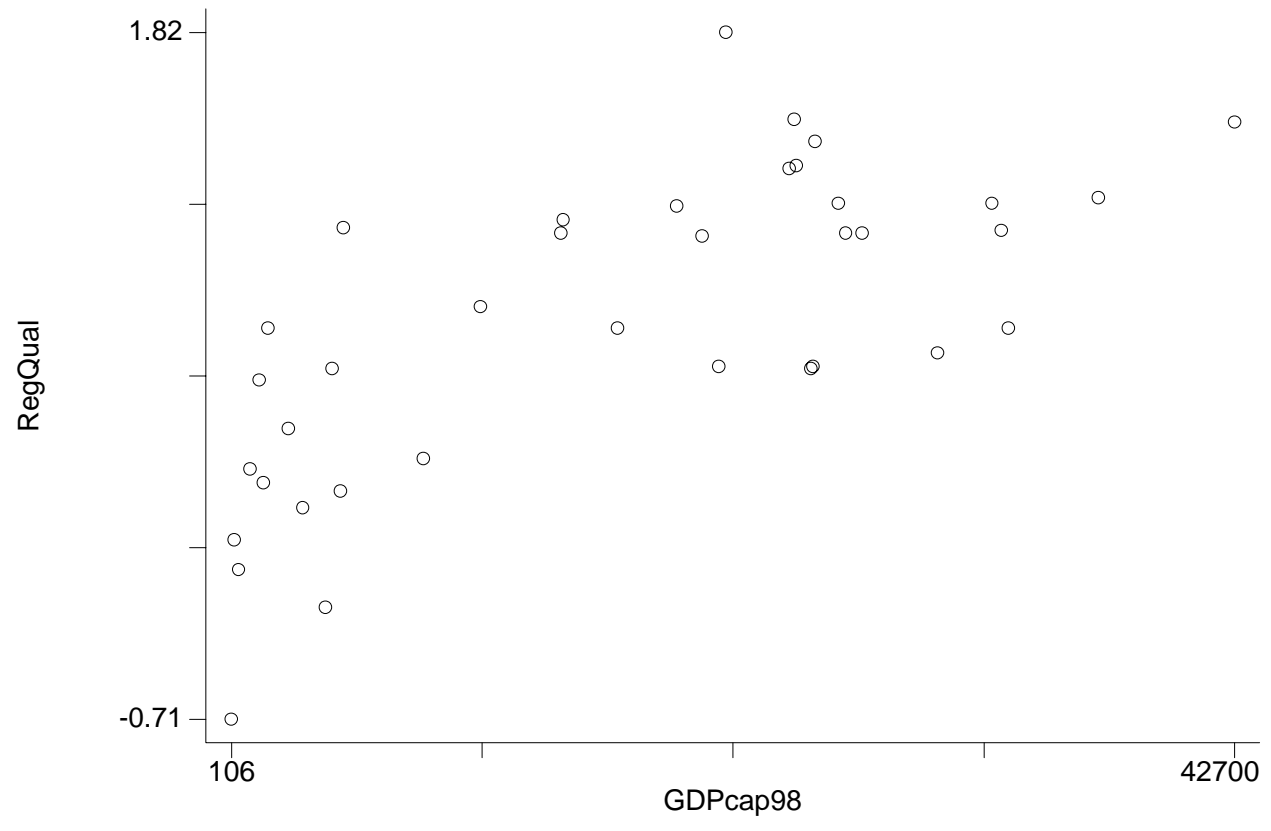

\section{Econometric Results of the Determinants of Endogenous Policies}

In Tables 3 and 4 we show the estimates for the determinants of entry barriers for two alternative specifications. Among the variables initially explored, we do not use the procedures measure, the Henisz index, and the government effectiveness index, because given the relatively low number of observations, we find it more valuable to focus on a low number of institutional variables and the ones discarded in this exercise did not yield significant results in any specification and/or were highly correlated with other variables. Table 2 presents descriptive statistics of the explanatory variables used in the regressions:

\section{Table 2}

Descriptive Statistics

\begin{tabular}{|c|c|c|c|c|c|}
\hline Variable | & Obs & Mean & Std. Dev. & Min & Max \\
\hline legal | & 37 & 2.108108 & 1.349563 & 0 & 4 \\
\hline iddummy | & 37 & 0.3243243 & 0.474579 & 0 & 1 \\
\hline gdpcap98| & 37 & 16429.59 & 12443.89 & 106.0387 & 42730.66 \\
\hline regqual| & 37 & 0.7502703 & 0.5706063 & -0.71 & 1.82 \\
\hline rulelaw | & 37 & 0.9137838 & 0.8469499 & -0.82 & 2 \\
\hline subsworker94| & 37 & 168.5808 & 74.31412 & 12.06927 & 294.625 \\
\hline lines10098 | & 37 & 38.33343 & 23.86969 & 0.27518 & 72.157 \\
\hline staff94 | & 37 & 0.1956929 & 0.1152364 & 0.0097726 & 0.3859936 \\
\hline urbanpop94 | & 37 & 71.34054 & 20.38853 & 13.1 & 100 \\
\hline
\end{tabular}


In Table 3, where the principal components index of entry barriers does not include the percentage of private ownership of the incumbent, legal origins and lagged performance appear to be significant and positive determinants of the index in some of the specifications. These effects maintain their magnitude and sign as we add other explanatory variables although they tend to lose significance. ${ }^{15}$ Our estimates are consistent with the hypothesis that less interventionist societies tend to have lower entry barriers to a larger extent, and impose regulations that favor the incumbents to a lesser degree. Societies with better telecommunications services also tend to lower barriers to a larger extent, although this is a weaker result in terms of robustness. The ideology of reforming governments appears to have no impact on the decision to lower barriers. Telecommunications entry does not appear to be a partisan policy. This would not be incompatible with some aspects of the reform process being partisan, but overall, reform in the sense of favoring entry through a variety of dimensions is not partisan according to our data. Adding the variable GDP per capita to the regressors does not change the results nor is it significant in itself, so we conclude that entry barriers are unrelated to the country's level of development.

\section{Table 3}

Parameter Estimates of Entry Barriers (OLS)

\begin{tabular}{|c|c|c|c|c|}
\hline \multirow{2}{*}{$\begin{array}{c}\text { Explanatory } \\
\text { Variables }\end{array}$} & \multicolumn{4}{|c|}{ Dependent Variable: entry(pc) } \\
\hline & (1) & (2) & (3) & (4) \\
\hline legal & $0.091 *(1.73)$ & $0.091^{*}(1.70)$ & $0.07 \quad(1.24)$ & $0.077 \quad(1.14)$ \\
\hline ideology & $-0.05 \quad(-0.33)$ & $-0.06 \quad(0.38)$ & $-0.044(-0.27)$ & $-0.014(-0.08)$ \\
\hline gdpcap98 & & & $0.001 \quad(0.10)$ & $-0.001(-1.04)$ \\
\hline regqual & & & & $0.319 \quad(1.18)$ \\
\hline rulelaw & & & & $-0.163 \quad(-0.72)$ \\
\hline subsworker94 & $0.002^{* *}(2.08)$ & $0.001(1.36)$ & $(0.61)$ & $0.000 \quad(0.0)$ \\
\hline lines10098 & & & $0.001 \quad(1.07)$ & $0.02 \quad(0.99)$ \\
\hline staff94 & & & & $-1.161(-0.52)$ \\
\hline urbanpop & & $0.001 \quad(0.22)$ & & $-0.001(-0.20)$ \\
\hline intercept & $-0.517^{* \star}(-2.67)$ & $-0.56^{\star \star}(-2.04)$ & $-0.537^{*}(-1.89)$ & $-0.393(-1.21)$ \\
\hline $\begin{array}{l}\text { White test } \\
\text { (p-value) }\end{array}$ & $\begin{array}{c}6.97 \\
(0.5400)\end{array}$ & $\begin{array}{c}9.56 \\
(0.7293) \\
\end{array}$ & $\begin{array}{c}17.13 \\
(0.5810)\end{array}$ & $\begin{array}{c}37.00 \\
(0.4226) \\
\end{array}$ \\
\hline VIF (mean) & 1.04 & 1.56 & 4.58 & 9.94 \\
\hline R square & 0.21 & 0.21 & 0.24 & 0.28 \\
\hline Adjusted R square & 0.13 & 0.11 & 0.08 & 0.04 \\
\hline
\end{tabular}

Notes: t-statistics in parentheses, unless otherwise indicated; significance at $10 \%$ level: *; significance at 5\% level: **; significance at $1 \%$ level: ***. The White test is a standard test statistic under the null hypothesis of homoskedasticity. VIF (mean) reports the mean of the variance inflation factors. The number of observations in all regressions is 37.

${ }^{15}$ In Tables 3, 4, 5 and 6, we report, for each regression, the results of the White test for heteroskedasticity, and the mean of the variance inflation factor (VIF) as a measure of multicolinearity. A VIF value lower than ten, is taken, as a practical rule, as descriptive of an absence of multicolinearity (see for example Gujarati, 1997). All figures are within reasonable values, so we cannot reject the hypotheses of homoskedasticity and absence of multicolinearity. We performed basic tests of serial correlation, which we do not report, without any significant result. These basic tests, such as Durbin-Watson, require the specification of a specific pattern. Serial correlation in a cross section may be due to spatial patterns, omitted variables or incorrect functional form, but it is less frequent than in time series. Since our results are already robust to several excluded and included variables, and in any case given our low number of observations, we have tried to keep the number of variables at a low level. 
In Table 4, the entry index includes the percentage of private ownership. This reinforces the impact of legal origin as a determinant of entry barriers, since now the legal origin variable is statistically significant in all specifications. This reflects the fact that countries that have a less interventionist judicial tradition are more prone to open up their telecommunications sectors, including selling a large share, and possibly all of it, to the private sector. The ideology variable, however, again has no significant impact on entry barriers, even when we measure this including privatization.

As we saw in Table 1, our index of regulatory independence is not highly correlated with any of the other institutional indices, and in particular it is not correlated with overall regulatory quality. We interpret this as evidence that formal regulatory independence is compatible with different levels of general regulatory or institutional quality. However, this does not mean that regulatory independence does not show any systematic pattern.

\section{Table 4}

Parameter Estimates of Entry Barriers Including Privatization (OLS)

\begin{tabular}{|c|c|c|c|c|}
\hline \multirow{2}{*}{$\begin{array}{c}\text { Explanatory } \\
\text { Variables }\end{array}$} & \multicolumn{4}{|c|}{ Dependent Variable: entry/p(pc) } \\
\hline & (1) & (2) & (3) & (4) \\
\hline legal & $0.11^{* *} \quad(2.64)$ & $0.11^{* *} \quad(2.60)$ & $0.11^{* *}(2.35)$ & $0.11^{\star *}(2.24)$ \\
\hline ideology & $-0.06 \quad(-0.52)$ & $-0.08 \quad(-0.67)$ & $-0.06 \quad(-0.52)$ & $-0.05(-0.41)$ \\
\hline gdpcap98 & & & $-0.01(-1.20)$ & $-0.01(-1.32)$ \\
\hline regqual & & & & $0.27 \quad(1.32)$ \\
\hline rulelaw & & & & $-0.17(-1.00)$ \\
\hline subsworker94 & $0.002^{* *} \quad(2.18)$ & $0.001 \quad(1.20)$ & $0.001 \quad(1.40)$ & $0.001 \quad(0.10)$ \\
\hline lines10098 & & & $0.01 \quad(0.89)$ & $0.02(1.18)$ \\
\hline staff94 & & & & $-1.38(-0.81)$ \\
\hline urbanpop & & $0.01 \quad(0.57)$ & & $0.01 \quad(0.02)$ \\
\hline intercept & $-0.48^{* * *}(-3.21)$ & $-0.56^{* *}(-2.68)$ & $\begin{array}{l}-0.53^{* * *} \\
(-3.21)\end{array}$ & $-0.44^{*}(-1.81)$ \\
\hline $\begin{array}{l}\text { White test } \\
\text { (p-value) }\end{array}$ & $\begin{array}{c}8.22 \\
(0.4125) \\
\end{array}$ & $\begin{array}{c}9.56 \\
(0.7293) \\
\end{array}$ & $\begin{array}{c}15.45 \\
(0.6937)\end{array}$ & $\begin{array}{c}37.00 \\
(0.4226)\end{array}$ \\
\hline VIF (mean) & 1.04 & 1.56 & 4.58 & 9.94 \\
\hline R square & 0.30 & 0.30 & 0.33 & 0.38 \\
\hline Adjusted R square & 0.23 & 0.22 & 0.22 & 0.18 \\
\hline
\end{tabular}

Notes: t-statistics in parentheses; significance at $10 \%$ level: $*$; significance at $5 \%$ level: **; significance at $1 \%$ level: ***. The White test is a standard test statistic under the null hypothesis of homoskedasticity. VIF (mean) reports the mean of the variance inflation factors. The number of observations in all regressions is 37.

Our regression results on the determinants of independence (see Tables 5 and 6) show that independence is a substitute for other ways of achieving commitment not to expropriate. In particular, the respect for the rule of law $^{16}$ (which has a negative sign and is significant in the four specifications we report both in Table 5, where the independence index includes

${ }^{16}$ We report regression results using the principal components indices. The qualitative interpretation, sign and significance of results are unchanged if we instead use the indices computed adding up the original variables. 
privatization, and in Table 6, where the independence index does not include privatization) and the presence of right wing pro-capital governments (which has a negative sign in the four specifications and is significant in three of them both in Table 5 and in Table 6) appear to be negatively and in most cases significantly related to the creation of independent regulatory agencies. This is consistent with the Levy and Spiller (1996) view of regulatory commitment and credibility. Countries achieve regulatory commitment not to expropriate investment, yielding good results in terms of industry performance, if they are able to create credible institutions that are well adapted to the institutional endowment of each country. Since institutional endowments vary across countries, the way different countries set up commitment institutions (through legislation, contracts or independent regulation) will vary. ${ }^{17}$

In Chile, for example, with a presidential system and coalition governments, it is very difficult to change legislation, so that commitment is achieved through very detailed laws which, as anticipated at the time of reform, would make setting up a regulatory independent agency redundant and hence not cost effective if there is any cost to independence (for example in terms of political legitimacy or other costs to the political principals). Hence Chile is one of the few countries in our data set that does not even have a separate telecom regulator.

In some of our regressions (significantly in two of the four specifications both in Table 5 and in Table 6, and with a positive sign in three of the specifications in Table 4 and in all in Table 6), the effect of the size of the incumbent (as measured by the number of telecommunications staff some years before the year in which independence is measured, namely in 1994) has a positive and statistically significant effect on the decision to create an independent regulatory agency.

This is a surprising result, and we could interpret it as the incumbent preferring an independent regulator in the face of the forthcoming liberalization, which will inevitably be associated with more interest group competition. This is consistent with the view of Henisz and Zelner (2000) on the electricity industry, where they show that incumbents lobby for the creation of constraints on investment expropriation if they foresee strong interest group competition. Adding the variable GDP per capita among the regressors does not change the results nor is it significant in itself, so we conclude that setting up legally independent regulatory agencies is unrelated to the level of development.

\footnotetext{
${ }^{17}$ The U.K. set up independent regulators with a right wing government and high quality rule of law. However, in many ways it is a special case. With its centralized system and first-pass-the-post electoral system, it has very few constraints on the executive's behaviour, so that new and special institutions, such as an independent regulator, must be put in place to achieve commitment. The way the independent regulator is set up takes advantage of other features of the British institutional endowment, such as the respect for contracts and the independence of the judiciary. See Vogelsang and Spiller (1997).
} 


\section{Table 5}

Estimates of Regulatory Independence Including Privatization (OLS)

\begin{tabular}{|c|c|c|c|c|}
\hline \multirow{2}{*}{$\begin{array}{l}\text { Explanatory } \\
\text { Variables }\end{array}$} & \multicolumn{4}{|c|}{ Dependent Variable: indep/p(pc) } \\
\hline & (1) & (2) & (3) & (4) \\
\hline legal & & & & $-0.064(-1.17)$ \\
\hline ideology & $-0.219^{*}(-1.71)$ & $-0.235^{\star}(-1.83)$ & $-0.231^{*}(-1.82)$ & $-0.202(-1.46)$ \\
\hline gdpcap98 & & & $0.001(0.77)$ & $0.001 \quad(0.06)$ \\
\hline regqual & & $0.247 \quad(1.28)$ & $0.254(1.32)$ & $0.352 \quad(1.61)$ \\
\hline rulelaw & $-0.205^{\star}(-2.00)$ & $-0.402^{* \star}(-2.45)$ & $-0.398^{\star \star}(-2.50)$ & $-0.381^{* *}(-2.10)$ \\
\hline subsworker94 & & & & $-0.004(-1.69)$ \\
\hline lines10098 & & $0.005 \quad(0.71)$ & & $0.019 \quad(1.20)$ \\
\hline staff94 & $1.954^{\star *}(2.58)$ & $1.30 \quad(1.16)$ & $1.61^{*}(1.93)$ & $-0.231(-0.13)$ \\
\hline urbanpop & & & & $0.002 \quad(0.39)$ \\
\hline intercept & $-0.124 \quad(-0.99)$ & $-0.191 \quad(-1.45)$ & $-0.182(-1.39)$ & $0.123 \quad(0.47)$ \\
\hline $\begin{array}{l}\text { White test } \\
\text { ( } p \text {-value) }\end{array}$ & $\begin{array}{c}11.56 \\
(0.1721)\end{array}$ & $\begin{array}{c}20.29 \\
(0.3772)\end{array}$ & $\begin{array}{c}17.97 \\
(0.5241)\end{array}$ & $\begin{array}{c}37.00 \\
(0.4226)\end{array}$ \\
\hline VIF (mean) & 1.72 & 4.51 & 3.12 & 9.94 \\
\hline $\mathrm{R}$ square & 0.22 & 0.28 & 0.28 & 0.3807 \\
\hline Adjusted $\mathrm{R}$ square & 0.16 & 0.17 & 0.17 & 0.1743 \\
\hline
\end{tabular}

Notes: $\mathrm{t}$-statistics in parentheses; significance at $10 \%$ level: *; significance at $5 \%$ level: **; significance at $1 \%$ level: ***. The White test is a standard test statistic under the null hypothesis of homoskedasticity. VIF (mean) reports the mean of the variance inflation factors. The number of observations in all regressions is 37.

\section{Table 6}

Parameter Estimates of Regulatory Independence (OLS)

\begin{tabular}{|c|c|c|c|c|}
\hline \multirow{2}{*}{$\begin{array}{c}\text { Explanatory } \\
\text { Variables }\end{array}$} & \multicolumn{4}{|c|}{ Dependent Variable: indep(pc) } \\
\hline & (1) & (2) & (3) & (4) \\
\hline legal & & & & $-0.11^{*}(-1.90)$ \\
\hline ideology & $-0.27^{*}(-1.86)$ & $-0.27^{*}(-1.89)$ & $-0.28^{*}(-1.96)$ & $-0.22 \quad(-1.49)$ \\
\hline gdpcap98 & & & $0.01 \quad(0.71)$ & $0.01 \quad(0.51)$ \\
\hline regqual & & $0.30 \quad(1.36)$ & $0.29 \quad(1.36)$ & $0.45^{\star} \quad(1.91)$ \\
\hline rulelaw & $-0.21^{*}(-1.85)$ & $-0.40^{* *}(-2.15)$ & $-0.43^{* *}(-2.40)$ & $-0.36^{*}(-1.84)$ \\
\hline subsworker94 & & & & $-0.01^{*}(-1.91)$ \\
\hline lines10098 & & $0.01(0.24)$ & & $(0.82)$ \\
\hline staff94 & $2.07^{* *}(2.43)$ & $1.76(1.39)$ & $1.70^{*}(1.81)$ & $(0.20)$ \\
\hline urbanpop & & & & $(0.33)$ \\
\hline intercept & $-0.12 \quad(-0.87)$ & $-0.19(-1.27)$ & $-0.19 \quad(-1.29)$ & $(0.94)$ \\
\hline $\begin{array}{l}\text { White test } \\
\text { ( } p \text {-value) }\end{array}$ & $\begin{array}{c}10.42 \\
(0.2370)\end{array}$ & $\begin{array}{c}20.52 \\
(0.3641)\end{array}$ & $\begin{array}{c}16.95 \\
(0.5935)\end{array}$ & $\begin{array}{c}37.00 \\
(0.4226)\end{array}$ \\
\hline VIF (mean) & 1.72 & 4.51 & 3.12 & 9.94 \\
\hline R square & 0.2213 & 0.27 & 0.28 & 0.30 \\
\hline Adjusted $\mathrm{R}$ square & 0.1506 & 0.15 & 0.16 & 0.23 \\
\hline
\end{tabular}

Notes: t-statistics in parentheses; significance at $10 \%$ level: *; significance at $5 \%$ level: **; significance at $1 \%$ level: ***. The White test is a standard test statistic under the null hypothesis of homoskedasticity. VIF (mean) reports the mean of the variance inflation factors. The number of observations in all regressions is 37. 
To sum up, the data do not reject the part of hypothesis 1 that predicts that entry barriers are related to the non-interventionist tradition of countries, or the part of hypothesis 2 that predicts that regulatory independence is determined by the institutional endowment of countries. We also find (weaker) support for the part of hypothesis 2 that predicts that independence is associated with interest group pressure. In this case, we find that countries with a larger incumbent are more prone to create independent agencies, although this result is not statistically as strong as the previous one. We conjecture that large incumbents may find that independent specialized regulators (with staff members probably recruited among previous incumbent staff) may be more easily captured than governments, and/or that large incumbents may have more to lose without an independent regulator, if the independent regulator, as a credible commitment device, contributes to alleviating the under-investment problem. This is so because larger incumbents have larger sunk investments in infrastructures. Larger data-sets with a longer time horizon will confirm, or not, this conjecture.

Regulatory quality has a positive impact on independence, although this is significant in only one of the specifications. If additional data confirms this result, we could interpret the evidence as telling us that, among those countries that have low ability to commit through other means, those with better regulatory quality will at least be able to create sustainable independent regulatory agencies.

The correlation coefficient between the principal components index of independence with the original privatization variable (the one used in Table 5) and the one without this original variable (the one in Table 6) is 0.9625 .

The correlation coefficient between the principal components index of entry without the original privatization variable (which we used in Table 3) and the one with this original variable (which we used in Table 4) is 0.9613. Hence there does not seem to be a big difference between including privatization in the entry barriers dimension and including it in the independence dimension.

It is easy to find arguments as to why privatization should be either part of independence or of entry barriers. One can include it in the package of independence policies if one thinks that private ownership of the incumbent further separates the government from the operators it is to regulate. Or one can include it in the entry barriers package if one thinks that opening up the capital of the incumbent to private ownership is part of the policy to stop a tradition of favoring incumbents using public policy. 


\section{Conclusions}

In this study, we provide a new data set that allows us to measure telecommunications reforms carefully and rank countries according to their policies, and we clarify in statistical terms which are the likely determinants of the creation of independent agencies and the determinants of entry barriers. ${ }^{18}$ Our main conclusions about these issues can be summarized as follows:

1) Measurement and rankings. We present new data, in the form of several indices, on entry policies and the independence of regulators for a cross section of countries. These indices take into account the multi-dimensionality of policies and institutions. In the case of independence, this moves the empirical literature on regulation one step closer to the empirical literature on central bank independence in monetary policy, where the use of independence indices as opposed to dummy variables has become common practice.

2) Political and institutional determinants. Policies are endogenous. Our indices were combined with a comprehensive set of performance, institutional and political data to quantify the determinants of telecommunications policies. We found that entry barriers are positively associated with the degree to which countries have an interventionist tradition, but not with the partisan ideology of reforming governments. We also found that countries with weak protection of the investors' quasi-rents by other means, and countries with a larger incumbent, are more prone to create independent regulatory agencies, although the latter is a statistically weaker result. The effect of the institutional endowment is consistent with the previous literature on regulatory institutions. The positive association between incumbent size and independent regulators may seem puzzling. We conjecture that large incumbents may find that independent specialized regulators (with staff members probably recruited among previous incumbent staff) may be more easily captured than governments, and/or that large incumbents may have more to lose without an independent regulator, if the independent regulator contributes to alleviating the under-investment problem. This is the case because larger incumbents have larger sunk investments in infrastructures.

Future research should focus on the impact in practice of effective regulatory agencies. Gutiérrez (2003) takes a first step in this direction. Despite the importance of creating politically sustainable regulatory systems, the establishment of separate regulatory agencies in telecommunications is still a very recent phenomenon, and it deserves further scrutiny.

\footnotetext{
${ }^{18}$ In a previous extended version of this article (see Gual and Trillas, 2004) we also explored the statistical impact of independence and entry on network penetration and partial productivity indicators. However, the results in this respect were weak. We argued there that, if the endogeneity of policies is not taken into account, misleading results may be obtained (along the lines of Duso and Röller, 2003, and Besley and Case, 2000). It is probably too early to reach any final conclusion on the effects of different market opening and regulatory independence policies. The initial results with this data set point to a positive effect of entry policies on network penetration and a negative effect of regulatory independence on productivity, although the results are not always robust. More observations and better performance data will be needed to make progress in the overall assessment. As Stern and Cubbin (2003) argue: "Given the time needed to establish the effective working of regulatory institutions - let alone the time needed to establish their reputation and credibility - it is hardly surprising that, as yet, it has been difficult to make any robust estimates of the impact of regulation on outcomes."
} 


\section{References}

Alesina, A. and H. Rosenthal (1995) Partisan Politics, Divided Government and The Economy, Cambridge University Press, Cambridge, MA.

Armstrong, M. and D. Sappington (2005) "Regulation, Competition and Liberalization," forthcoming in Journal of Economic Literature.

Armstrong, M. and D. Sappington (2003) "Recent Developments in The Theory of Regulation," forthcoming in Handbook of Industrial Organization, vol. III.

Bandiera, O., G. Caprio, P. Honohan, and F. Sciantarelli (2000) "Does Financial Reform Raise or Reduce Saving?" The Review of Economics and Statistics, 82(2): 239-263.

Beck, T., G. Clarke, A. Groff, P. Keefer and P. Walsh (2001) "New Tools in Comparative Political Economy,” World Bank Economic Review, 15: 165-176.

Besley, T. and A. Case (2000) "Unnatural Experiments? Estimating the Incidence of Endogenous Policies,” The Economic Journal, 110: F672-F694.

Boylaud, 0. and G. Nicoletti (2000) "Regulation, Market Structure and Performance in Telecommunications,” OECD Econ. Dept. working paper 237, Paris.

Donald, S. G. and D. Sappington (1995) "Explaining the Choice among Regulatory Plans in the U.S. Telecommunications Industry," The Journal of Economics and Management Strategy, 4(2): 237-265.

Duso, T. and L.-H. Roeller (2003) "Endogenous Deregulation: Evidence from OECD Countries," Economics Letters, 81 (1): 67-71.

Edwards, G. and L. Waverman (2006) "The Effects of Public Ownership and Regulatory Independence on Regulatory Outcomes. A Study of Interconnect Rates in EU Telecommunications," Journal of Regulatory Economics, 29(1): 23-67.

Fink, C., A. Mattoo and R. Rathindran (2002) "An Assessment of Telecommunications Reform in Developing Countries,” The World Bank, mimeo.

Grossman, G. M. and E. Helpman (2001) Special Interest Politics, The MIT Press, Cambridge.

Gual, J. and F. Trillas (2004) "Telecommunications Reform: Determinants and Impact," CEPR Discussion Paper, 4578.

Gujarati, D. N. (1997) Basic Econometrics, Third Edition, McGraw-Hill.

Gutiérrez, L. H. (2003) "The Effect of Endogenous Regulation on Telecommunications Expansion and Efficiency in Latin America," Journal of Regulatory Economics, 23 (3): 257-286.

Henisz, W. J. and B.A. Zelner (2000a) "The Institutional Environment for Telecommunications Investment," Journal of Economics and Management Strategy, 10(1): 123-147.

Henisz, W. J. and B.A. Zelner (2000b) "Political Constraints, Interest Group Competition and Infrastructure Investment in the Electric Utility Industry: A Cross-National Study," mimeo, WP-00-03, Reginald H. Jones Center, The Wharton School, University of Pennsylvania. 
Kaufmann, D. and A. Kraay (2002) “Growth without Governance”, mimeo, The World Bank.

La Porta, R., F. López de Silanes, A. Shleifer and R. Vishny (1999) "The Quality of Government," Journal of Law, Economics and Organization, 15(1): 222-279.

La Porta, R., F. López de Silanes, A. Shleifer and R. Vishny (2002) “The Regulation of Entry," mimeo.

Levine, P., J. Stern and F. Trillas (2005) "Utility Price Regulation and Time Inconsistency: Lessons from Monetary Policy,” Oxford Economic Papers, 57: 447-478.

Levy, B. and P.T. Spiller (1996) Regulation, Institutions, and Commitment: Comparative Studies of Telecommunications, Cambridge University Press.

Li, W., Q. Zhen-Wei and L. Colin Xu (2002) "The Political Economy of Privatization and Competition: Cross-Country Evidence from the Telecommunications Sector," Journal of Comparative Economics, 30(3): 439-462.

Peltzman, S. (1976) "Toward a More General Theory of Regulation," Journal of Law and Economics, 19: 211-240.

Persson, T. and G. Tabellini (2000), Political Economics. Explaining Economic Policy. The MIT Press.

Ros, A. J. (2003), "The Impact of the Regulatory Process and Price Cap Regulation in Latin American Telecommunications Markets”, Review of Network Economics, 2(3).

Sidak, G. and D. Spulber (1997) Deregulatory Takings and the Regulatory Contract, Cambridge University Press, Cambridge, MA.

Spiller, P. T. and I. Vogelsang (1997) "The Institutional Foundations of Regulatory Commitment in the UK: The Case of Telecommunications," Journal of Institutional and Theoretical Economics, 153(4): 607-29

Stern, J. and J. Cubbin (2003) “A Survey of Empirical Studies of Regulatory Governance," mimeo.

Stern, J. and F. Trillas (2003) "Independence and Discretion in Telecommunications Regulation: Lessons from Independent Central Banks,” Utilities Policy, 11: 191-201.

Wallsten, S. J. (2001) "An Econometric Analysis of Telecom Competition, Privatization, and Regulation in Africa and Latin America," The Journal of Industrial Economics, Vol. 49, No 1, March 2001, pages 1-19.

Wallsten, S. J. (2002) “Does Sequencing Matter?” WB DP 2817, The World Bank. 


\section{Appendix 1}

Original Policy Variables. Definition and Measurement ${ }^{19}$

Investment conditions imposed on entrants: equals 0 if entry to the industry is subjected to investment conditions of any kind and 1 otherwise. If there are no entrants, the value is set at 0 .

Average number of mobile providers: average of the number of providers in operation in 1996 and 1997.

Number portability. Fixed telephony: equals 0 if number portability in fixed telephony is not possible and 1 otherwise.

Carrier selection. Local: equals 0 if carrier selection of the local operator is not possible and 1 otherwise.

Carrier selection. Long distance and international: equals 0 if the carrier selection of the long distance operator (national and international) is not possible and 1 otherwise.

Carrier pre-selection. Local: equals 0 if carrier pre-selection of the local operator is not possible and 1 otherwise.

Carrier pre-selection. Long distance and international: equals 0 if carrier pre-selection of the long distance operator (national and international) is not possible and 1 otherwise.

Year of establishment of effective operation: equals 0 if the regulatory authority is a department of the government and grows with older year of establishment.

Private ownership of the incumbent (\%): percentage of the incumbent that is not owned directly by the government.

Local loop unbundling availability: equals 0 if local loop unbundling is not available and 1 otherwise.

Method of spectrum allocation: equals 0 if the mobile industry is under monopoly, 1 if the licensing process is on a "first come first served" basis, 2 if the spectrum allocation is done through comparative tenders, 3 if it is done through competitive tenders with a financial offer, and 4 if it is done through auctions.

Licensing: equals 1 if the regulator has the power to grant licenses and 0 if it is a function carried out only by a ministry. If the ministry is the only regulator, this variable is set to 0 as well.

Interconnection: equals 1 if the regulator has the power to establish and administrate interconnection regimes and 0 in the same situations as in the previous variable.

Tariffs: equals 1 if the regulator can determine regulated tariffs and 0 in the same situations as the previous variable.

Scarce resources: equals 1 if the regulator can administrate scarce resources, such as spectrum frequencies and numeration plans, and 0 in the same situations as before.

\footnotetext{
${ }^{19}$ Unless otherwise stated, the measurement refers to the situation at the beginning of 1998 . The original data on which the indices are based is available upon request.
} 


\section{Appendix 1 (continued)}

Universal service: equals 1 if the regulator can establish and administrate a universal service and 0 in the same situations as before.

Funding: equals 0 if the regulator gets its funds from the government budget, 1 if it also gets fees from the operators and 2 if the funding is only through fees paid by the operators.

Appointed by: equals 0 if the head of the regulatory authority is appointed directly by the government, 1 if he/she is appointed by the government and the legislature and 2 if he/she is appointed only by the legislature. If the regulatory authority is a department of the government, it takes a value of 0 .

Length of term: years of the term in office for the regulator. If the regulatory authority is a department of the government or its term is not defined, the value is set to 0 .

Reporting to: equals 0 if the regulatory authority has to report to the government, 1 if it has to report to the government and to the legislature, 2 if it has to report only to the legislature and 3 if it reports to no one. 


\section{Appendix 2}

Construction of Indices

\section{A2.1. Entry and indep}

The entry and indep indices each use a number of original variables in the following way: First, the original variables are re-coded, so that each of the observations can be measured on a 0-1 range. This is done by dividing the original metric for each observation by the maximum value of the variable (for example, if Spain has a value of 2 in "method of spectrum allocation" the re-coded value will be $2 / 4=0.5$, where 4 is the maximum value that this original variable takes). Then the values of all the re-coded original variables used for the index are added for each country. Hence the final index will have a maximum value equal to the number of original variables used in its computation.

Entry uses as original variables: investment conditions imposed on entrants, average number of mobile providers, method of spectrum allocation, number portability (fixed telephony), number portability (mobile telephony), carrier selection (local), carrier selection (long distance and international), carrier pre-selection (local), carrier pre-selection (long distance and international), local loop unbundling.

Indep uses as original variables: licensing, interconnection, tariffs, scarce resources, universal service, funding, appointed by, term, reporting to, year of establishment of effective operation, private ownership of incumbent.

\section{A 2.2 Indep(pc) and entry(pc)}

These indices are computed using the principal components methodology. The original variables for each index are used to find the linear combinations that minimize the overall variance.

Indep (pc) uses as original variables: licensing, interconnection, tariffs, scarce resources, universal service, funding, appointed by, length of term, reporting to, year of establishment of effective operation, private ownership of the incumbent.

$\operatorname{Entry}(p c)$ uses as original variables: investment conditions imposed on entrants, average number of mobile providers, number portability (fixed telephony), carrier selection (local), carrier selection (long distance and international), carrier pre-selection (local), carrier preselection (long distance and international), local loop unbundling availability.

Principal components indices are obtained in both cases as follows. We describe the total variance of a set of $n$ points (the original variables) in $p$ dimensional space by introducing a new set of $p$ orthogonal and uncorrelated variates (the new indices). The new set is formed by taking normalized linear combinations of the original set so that the $r$ th variate generated has the $r$ th largest variance. 


\section{Appendix 2 (continued)}

The following tables show the numerical results for the computation of principal components, first for the set of "independence" variables, and second for the set of "entry barriers" variables. As it can be seen, for the independence components, the four first components explain 70\% of the variance. For the entry components, the three first components suffice to explain the same proportion of variance. ${ }^{20}$ This proportion is deemed sufficient in the principal components literature to retain the components that explain it.

\section{Table A1}

Total Variance Explained by Independence Components

Total Variance Explained

\begin{tabular}{|c|c|c|c|c|c|c|c|c|c|}
\hline & \multicolumn{3}{|c|}{ Initial Eigenvalues } & \multicolumn{3}{|c|}{ Extraction Sums of Squared Loadings } & \multicolumn{3}{|c|}{$\begin{array}{c}\text { Rotation Sums of Squared } \\
\text { Loadings }\end{array}$} \\
\hline Component & Total & $\begin{array}{c}\% \text { of } \\
\text { Variance }\end{array}$ & $\begin{array}{c}\text { Cumulative } \\
\%\end{array}$ & Total & $\begin{array}{c}\% \text { of } \\
\text { Variance }\end{array}$ & $\begin{array}{c}\text { Cumulative } \\
\%\end{array}$ & Total & $\begin{array}{c}\% \text { of } \\
\text { Variance }\end{array}$ & $\begin{array}{c}\text { Cumulative } \\
\% \\
\end{array}$ \\
\hline 1 & 3.675 & 33.408 & 33.408 & 3.675 & 33.408 & 33.408 & 2.466 & 22.419 & 22.419 \\
\hline 2 & 1.483 & 13.481 & 46.889 & 1.483 & 13.481 & 46.889 & 2.007 & 18.247 & 40.667 \\
\hline 3 & 1.337 & 12.154 & 59.043 & 1.337 & 12.154 & 59.043 & 1.767 & 16.065 & 56.732 \\
\hline 4 & 1.160 & 10.548 & 69.591 & 1.160 & 10.548 & 69.591 & 1.415 & 12.859 & 69.591 \\
\hline 5 & 0.987 & 8.971 & 78.563 & & & & & & \\
\hline 6 & 0.677 & 6.153 & 84.716 & & & & & & \\
\hline 7 & 0.531 & 4.828 & 89.544 & & & & & & \\
\hline 8 & 0.389 & 3.536 & 93.079 & & & & & & \\
\hline 9 & 0.316 & 2.870 & 94.950 & & & & & & \\
\hline 10 & 0.246 & 2.234 & 98.184 & & & & & & \\
\hline 11 & 0.200 & 1.816 & 100.000 & & & & & & \\
\hline
\end{tabular}

Extraction Method: Principal Component Analysis.

\section{Table A2}

Total Variance Explained by Entry Components

Total Variance Explained

\begin{tabular}{|c|c|c|c|c|c|c|c|c|c|}
\hline & \multicolumn{3}{|c|}{ Initial Eigenvalues } & \multicolumn{3}{c|}{ Extraction Sums of Squared Loadings } & \multicolumn{3}{c|}{$\begin{array}{c}\text { Rotation Sums of Squared } \\
\text { Loadings }\end{array}$} \\
\hline Component & Total & $\begin{array}{c}\text { \% of } \\
\text { Variance }\end{array}$ & $\begin{array}{c}\text { Cumulative } \\
\%\end{array}$ & Total & $\begin{array}{c}\% \text { of } \\
\text { Variance }\end{array}$ & $\begin{array}{c}\text { Cumulative } \\
\%\end{array}$ & Total & $\begin{array}{c}\text { \% of } \\
\text { Variance }\end{array}$ & $\begin{array}{c}\text { Cumulative } \\
\%\end{array}$ \\
\hline 1 & 3.562 & 39.583 & 39.583 & 3.562 & 39.583 & 39.583 & 2.240 & 24.884 & 24.884 \\
\hline 2 & 1.440 & 16.001 & 55.584 & 1.440 & 16.001 & 55.584 & 2.076 & 23.070 & 467.954 \\
\hline 3 & 1.373 & 15.252 & 70.836 & 1.373 & 15.252 & 70.836 & 2.059 & 22.883 & 70.836 \\
\hline 4 & 0.754 & 8.380 & 79.217 & & & & & & \\
\hline 5 & 0.597 & 6.630 & 84.846 & & & & & & \\
\hline 6 & 0.496 & 5.507 & 91.354 & & & & & & \\
\hline 7 & 0.396 & 4.399 & 95.753 & & & & & & \\
\hline 8 & 0.250 & 2.782 & 98.535 & & & & & & \\
\hline 9 & 0.132 & 1.465 & 100.000 & & & & & & \\
\hline
\end{tabular}

Extraction Method: Principal Component Analysis.

\footnotetext{
${ }^{20}$ Communalities, which measure the explanatory power of the original variables for the new components, and the Kaiser-Meyer-Oklin measure of sampling adequacy recommended dropping the following original variables before performing the principal components calculations for the entry variables: method of spectrum allocation, wireless local access licensing, number portability (mobile) and tariff rebalancing.
} 


\section{Appendix 3}

Rankings for the Indices of Liberalization and Regulatory Independence

\begin{tabular}{|c|c|c|c|c|c|c|c|}
\hline Country & indep & Country & indep(pc) & Country & entry & Country & entry(pc) \\
\hline U.S.A. & 9.381 & Canada & 0.6681662 & U.S.A. & 7.943 & Germany & 1.251928 \\
\hline Canada & 9.314285 & U.S.A. & 0.5222394 & Canada & 6.547812 & Finland & 1.179448 \\
\hline Denmark & 8.038095 & U.K. & 0.4021606 & Germany & 5.591839 & U.S.A. & 1.084524 \\
\hline Brazil & 7.847619 & Brazil & 0.3319355 & Finland & 4.896239 & Canada & 1.001984 \\
\hline Jordan & 7.838095 & Denmark & 0.3243424 & U.K. & 4.813 & U.K. & 0.5662228 \\
\hline Portugal & 7.778572 & Portugal & 0.2909521 & N. Zealand & 4.647 & Chile & 0.385118 \\
\hline Germany & 7.670952 & Philippines & 0.25991 & Chile & 4.558996 & Netherlands & 0.2778323 \\
\hline Venezuela & 7.538095 & Germany & 0.2591524 & Japan & 4.292 & Japan & 0.1531013 \\
\hline Philippines & 7.438095 & Norway & 0.2408735 & Netherlands & 3.803307 & Mexico & 0.1205352 \\
\hline Ireland & 7.333333 & Venezuela & 0.2373097 & Sweden & 3.581 & N. Zealand & 0.0938418 \\
\hline South Africa & 7.314286 & Sweden & 0.2330583 & Australia & 2.477045 & Sweden & 0.0354726 \\
\hline Singapore & 7.081429 & Singapore & 0.2318539 & Denmark & 2.472739 & Australia & -0.0068631 \\
\hline Madagascar & 6.627762 & Jordan & 0.2206925 & Italy & 2.4 & Singapore & -0.073858 \\
\hline U.K. & 6.514 & Bulgaria & 0.2159522 & Norway & 2.397585 & Austria & -0.1175417 \\
\hline Norway & 6.304762 & Netherlands & 0.2069955 & Mexico & 2.348204 & Switzerland & -0.1308754 \\
\hline Netherlands & 6.266762 & Italy & 0.184624 & Philippines & 2 & Brazil & -0.1309136 \\
\hline Sweden & 6.257 & Spain & 0.1844051 & Singapore & 1.857371 & Philippines & -0.1420536 \\
\hline Italy & 5.85 & Austria & 0.144458 & France & 1.572 & Italy & -0.1971367 \\
\hline Spain & 5.848 & Madagascar & 0.1413332 & Spain & 1.384 & France & -0.2011951 \\
\hline Belgium & 5.680476 & South Africa & 0.1392962 & Argentina & 1.349943 & Denmark & -0.2023769 \\
\hline Ethiopia (23) & 5.570875 & Peru & 0.050338 & Austria & 1.33373 & Argentina & -0.2082356 \\
\hline Austria & 5.514286 & Belgium & 0.0473781 & Switzerland & 1.237318 & Norway & -0.2127706 \\
\hline Switzerland & 5.471428 & Finland & 0.0279205 & Brazil & 1.237042 & Spain & -0.2272351 \\
\hline Bulgaria & 5.066667 & Ireland & 0.0044768 & Peru & 1.127565 & Bulgaria & -0.2281469 \\
\hline Finland & 4.450095 & Luxembourg & -0.0499222 & Bulgaria & 0.8342639 & Peru & -0.2677259 \\
\hline Peru & 4.404762 & Mexico & -0.0749068 & Luxembourg & 0.5878 & Venezuela & -0.2789819 \\
\hline Argentina & 4.247619 & Switzerland & -0.0872493 & Israel & 0.5067352 & Israel & -0.3011301 \\
\hline France & 4.204 & Ethiopia (23) & -0.1166388 & Jordan & 0.4902169 & Belgium & -0.3041749 \\
\hline Australia & 4.177619 & France & -0.2003275 & Belgium & 0.4847195 & Madagascar & -0.3055564 \\
\hline Morocco & 3.780952 & Morocco & -0.2034559 & Madagascar & 0.4747302 & Portugal & -0.3101694 \\
\hline Mexico & 3.751429 & Argentina & -0.2691715 & Morocco & 0.4628223 & Luxembourg & -0.3183601 \\
\hline Luxembourg & 3.561905 & Australia & -0.4477748 & Venezuela & 0.4505909 & South Africa & -0.321432 \\
\hline N. Zealand & 1 & India & -0.7238952 & Portugal & 0.4413747 & Ireland & -0.3243261 \\
\hline Chile & 1 & N. Zealand & -0.8243123 & South Africa & 0.3599385 & India & -0.3247177 \\
\hline India & 0.5619048 & Chile & -0.8243123 & Ireland & 0.3390125 & Jordan & -0.3321502 \\
\hline Israel & 0.46 & Israel & -0.8693424 & India & 0.3361807 & Morocco & -0.3359389 \\
\hline Japan & 0.35 & Japan & -0.8785152 & Ethiopia & 0.181269 & Ethiopia & -0.346142 \\
\hline
\end{tabular}

